\title{
Treatment of CMV retinitis in an AIDS patient
}

\author{
J F ACHESON,' S M SHAH,' D J SPALTON,' C BRADBEER,'? \\ AND R N THIN² \\ From the 'Medical Eye Unit and the ${ }^{2}$ Department of Genito-Urinary Medicine, St Thomas's Hospital, London \\ $S E 17 E H$
}

SUMMARY We present a case of cytomegalovirus (CMV) retinitis in an AIDS patient who survived for 10 months after the start of his ocular problems. The retinitis responded to dihydroxy propoxy methyl guanine (DHPG) but relapsed four to six weeks after each course of treatment with progressive retinal destruction. One relapse was therefore treated with trisodium phosphoformate hexahydrate (Foscarnet). There are few reports of the use of this drug in the treatment of CMV retinitis with AIDS, but it appeared to be less effective in our patient than DHPG, possibly because of poor penetration of the blood-ocular barrier. A final course of outpatient maintenance therapy with DHPG failed to prevent a preterminal relapse of the retinitis. Fundus photographs demonstrated the resolution and relapse of the retinitis associated with each course of treatment. Maintenance therapy with DHPG would appear to be necessary to prevent relapse, but the logistics of this are difficult, and the effective dosage of DHPG is as yet uncertain.

Patients with acquired immune deficiency syndrome are commonly found to have ocular lesions. Cottonwool spots, isolated retinal haemorrhages, conjunctival Kaposi's sarcoma, and cytomegalovirus (CMV) retinitis have been widely described. ${ }^{1-4}$ Other opportunistic infections occur less frequently and include cryptococcosis, toxoplasmosis, atypical mycobacterial infection, herpes simplex retinitis, and herpes zoster ophthalmicus. ${ }^{+7}$ In a large series of eyes taken at necropsy from 35 consecutive AIDS patients CMV retinitis was the commonest infection, being found in 12 cases (18 eyes, $34 \%$ ). ${ }^{8}$

The clinical features of CMV retinitis in AIDS are of progressive retinal destruction with fluffy white retinal infiltrates and intraretinal haemorrhages, often most marked along the major retinal vessels. Histologically there is full-thickness retinal necrosis with intracellular and intracytoplasmic inclusions. Virions may be identified on electron microscopy and virus antigen on indirect immunofluorescence. In AIDS it is not practical to confirm the diagnosis by obtaining intraocular specimens but the clinical diagnosis is supported by demonstrating cellular immune deficiency and human immunodeficiency virus (HIV, and also known as HTLV III/LAV) antibody in association with positive CMV serology or virus isolation from blood, urine, and secretions."

Correspondence to D J Spalton, FRCS.
Pepose et al.${ }^{8}$ have drawn attention to the frequent development of CMV retinitis in those AIDS patients with cotton-wool spots and propose that the cottonwool spots are a manifestation of an immune complex mediated microvasculopathy which allows cell-free and cell-associated cytomegalovirus to infect the retina by traversing damaged retinal endothelial cells. They also distinguish between a noninflammatory cytomegalovirus retinopathy seen in patients without AIDS and the cytomegalovirus retinitis seen in many patients with AIDS. In those with AIDS neutrophil function is preserved and may play a part in the progressive retinal necrosis of CMV retinitis. By contrast, infants, graft recipients, and patients with malignant disease often have defective neutrophil function, and when they develop disseminated CMV infection the retinopathy is less severe.

Experience of the specific treatment of disseminated CMV infection is limited, but over the past year remission of CMV pneumonitis, colitis, and retinitis in patients with immunodeficiency due to AIDS, allografts, and lymphoreticular neoplasms has been reported after administration of 9-(1,3dihydroxy-2-propoxymethyl) guanine (DHPG, Syntex Research) and of trisodium phosphoformate hexahydrate (Foscarnet, Astra Pharmaceuticals). DHPG is also known as BW B759U (Burroughs Welcome). We report our experience of the use of 


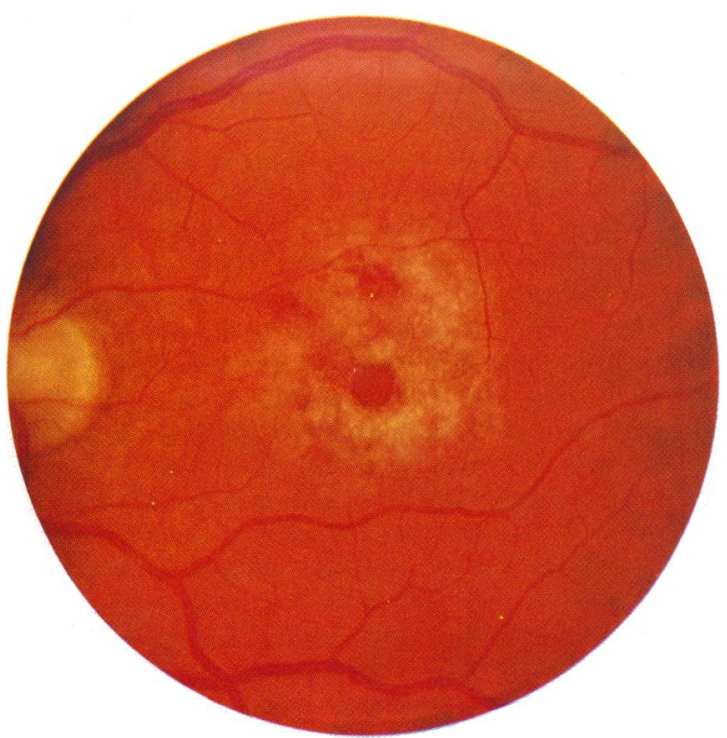

Figs. 1-7 Fundus photographs of the left macula and superotemporal retina demonstrate the retinopathy and effects of treatment and relapse.

Fig. 1 Fresh retinal infiltrates and haemorrhages at the macula before treatment.

both these agents in the treatment of one AIDS patient with relapsing CMV retinitis.

\section{Case report}

A 47-year-old male homosexual presented to the Eye Department in June 1985 with left visual loss. Seven weeks previously he had been treated with high-dose co-trimoxazole because of an atypical pneumonia presumed to be due to Pneumocystis carinii and at that time HIV antibody was demonstrated in the serum.

At presentation the right visual acuity was $6 / 5, \mathrm{~N} 5$, and the left was 6/36,N12. He read all the Ishihara colour plates correctly on the right and made four errors on the left. The eyes were white, and the anterior chambers were quiet. The right visual field, vitreous, and fundus was entirely normal. There was a dense central scotoma on the left side with a clearly demarcated 2-disc diameter area of intraretinal haemorrhages and white infiltrates at the macula. There were no cells in the left vitreous.

In July he developed oropharyngeal candidiasis and nystatin lozenges were prescribed. In late August the left visual acuity deteriorated to counting fingers, and fresh retinal lesions were seen (Fig. 1, 29 August 1985). A clinical diagnosis of CMV retinitis was made and dihydroxy propoxy methyl guanine (DHPG, Syntex Research) $10 \mathrm{mg} / \mathrm{kg} /$ day was administered for

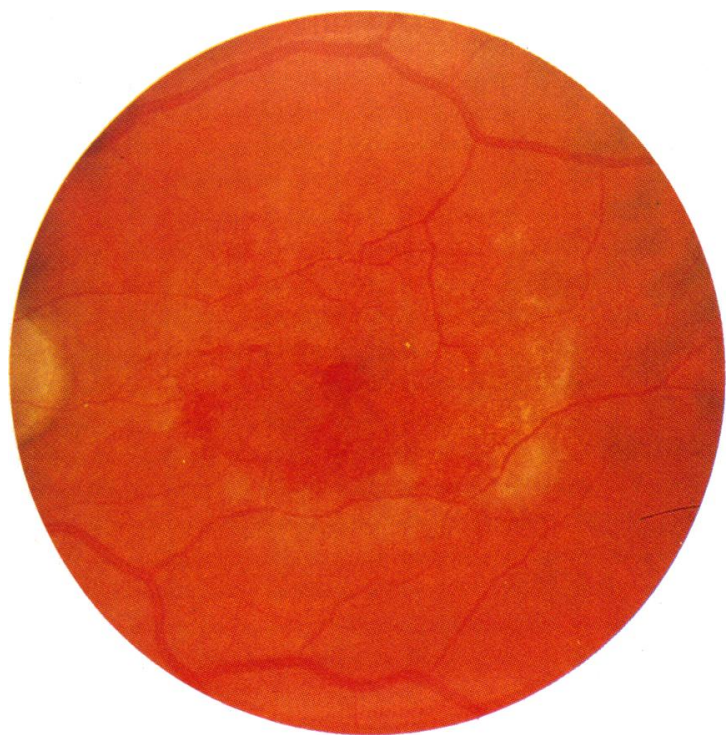

Fig 2A

Figs. 2A, B Good resolution of the retinitis after the first course of treatment with DHPG.

21 days. The retinitis improved without change in the visual acuity (Figs. 2A, B, 9 October 1985). The patient felt better and his weight improved. No systemic side effects of treatment were observed. The white cell count and neutrophil count remained normal at $5.8 \times 10^{9} / 1$ and $2.9 \times 10^{4} / 1$ respectively, but there was a persistent absolute lymphopenia of below $1.0 \times 10^{9} / 1$. He developed oesophageal candidiasis,

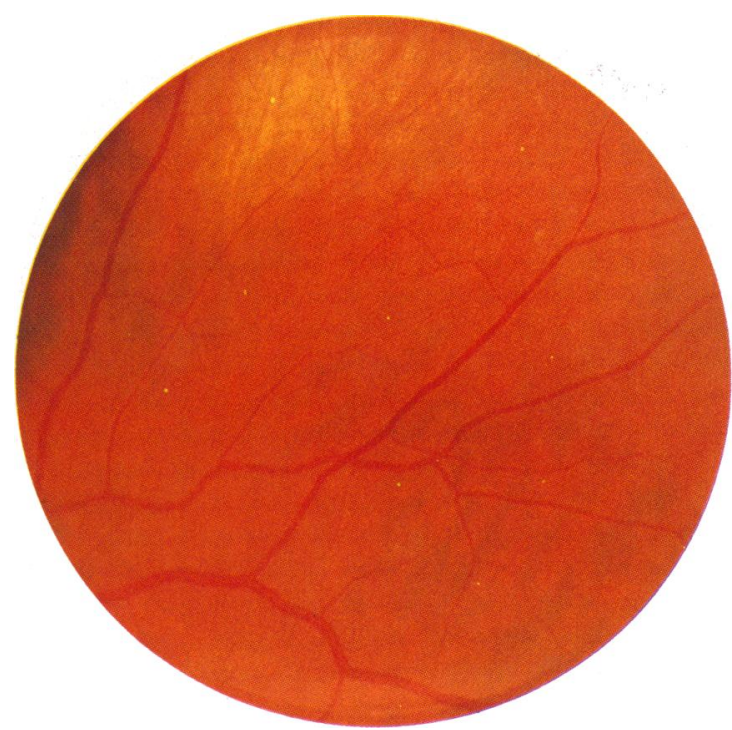

Fig. 2B 


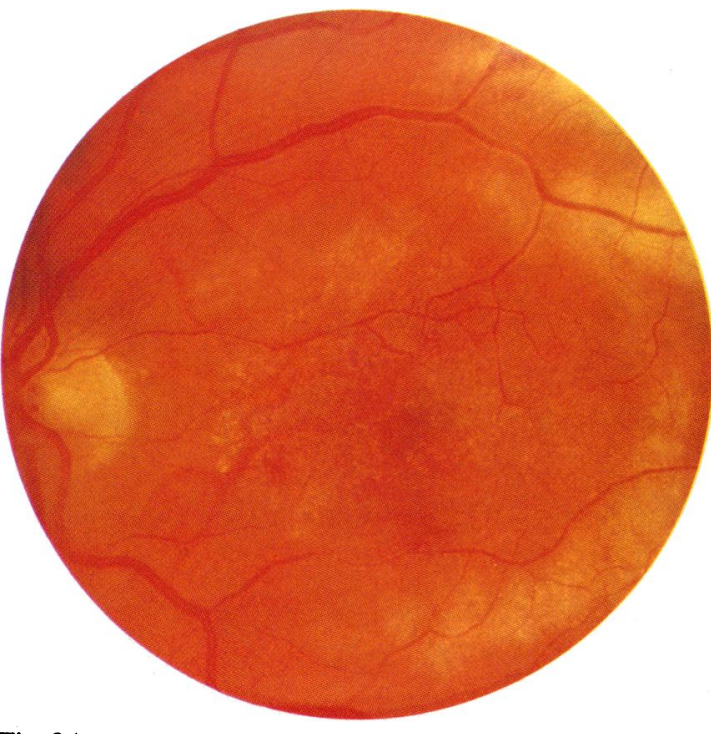

Fig. 3A

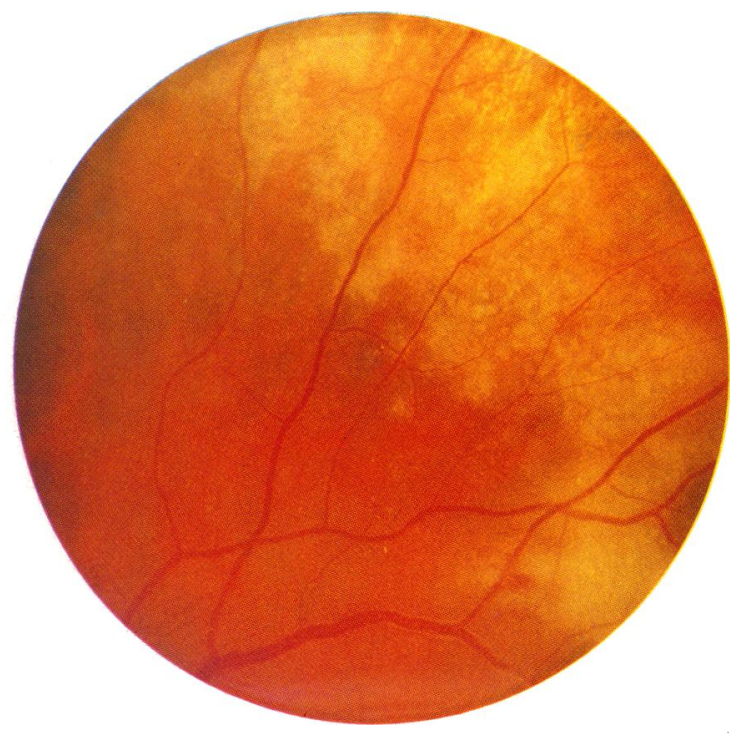

Fig. 3B

Figs. 3A, B Relapse and further retinal destruction in adjacent viable retina six weeks later.

which was treated with ketoconazole $200 \mathrm{mg}$ once daily.

Six weeks later, in November 1985, the right visual acuity fell to $6 / 36$, and fresh lesions consistent with CMV retinitis were seen in both eyes (Figs. 3A, B, 25 November 1985). CMV was isolated on cell culture from blood, urine, and a throat swab. BW B759U

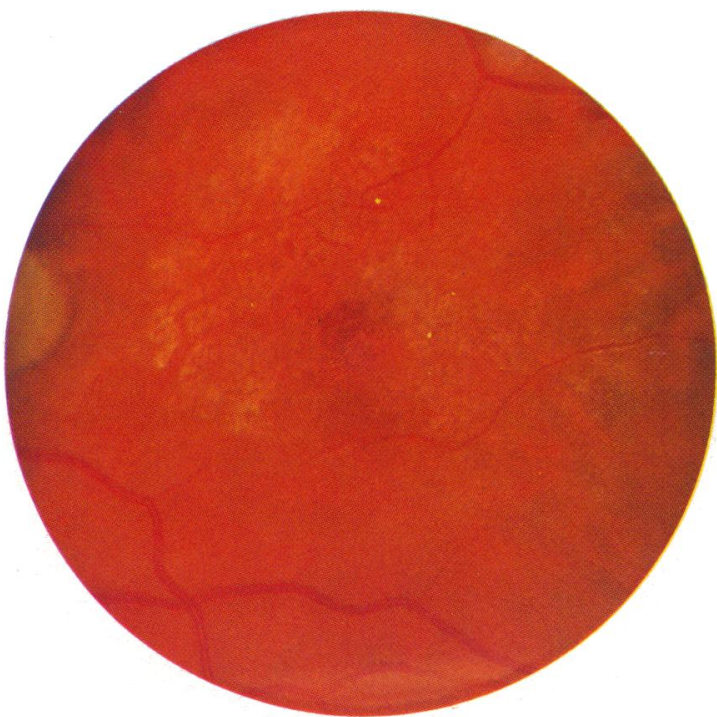

Fig. 4A

Fig. 4 A

Figs. 4A, B Resolution of the retinitis following a second course of DHPG. 


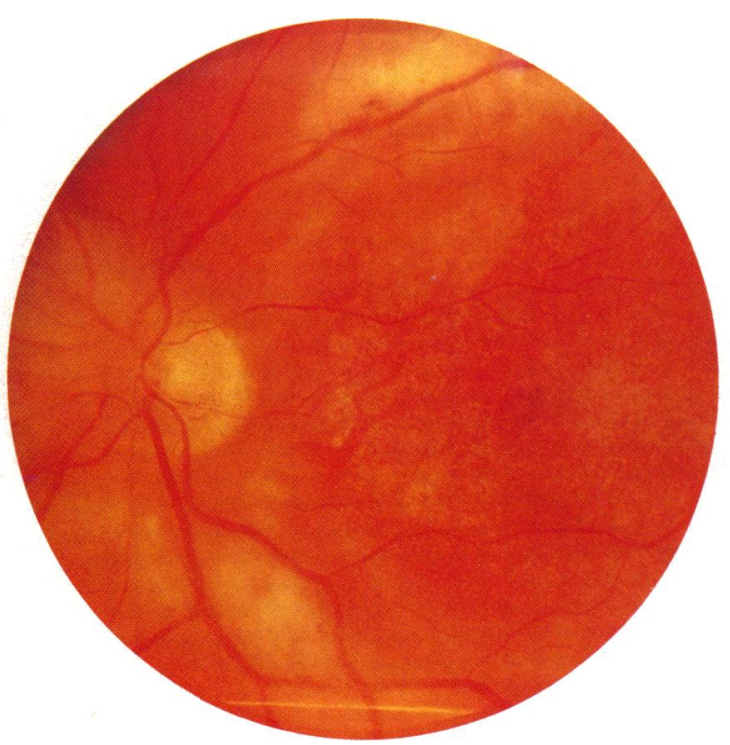

Fig. 5A

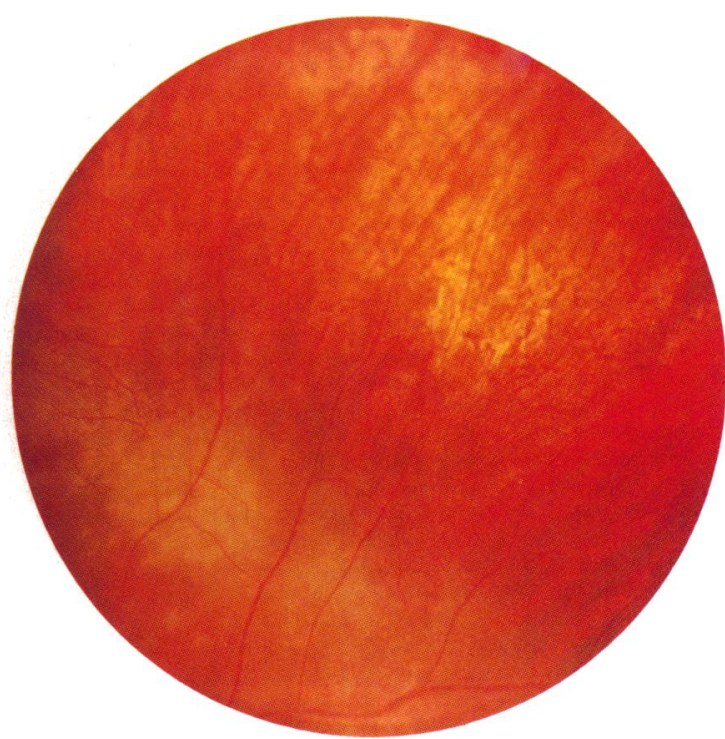

Fig. 5B

Figs. 5A, B Relapse and further retinal destruction four weeks later.

lesions were observed (Figs. 5A, B, 13 January 1986), and CMV was again isolated from urine. In view of the previous relapses after treatment with DHPG, Foscarnet $(1.5 \mathrm{~g}$ loading dose followed by $0 \cdot 15 \mathrm{mg} / \mathrm{kg} / \mathrm{min}$ ) was given intravenously for 19 days with only a marginal clinical response (Figs. 6A, B, 6 February 1986). The patient developed marked

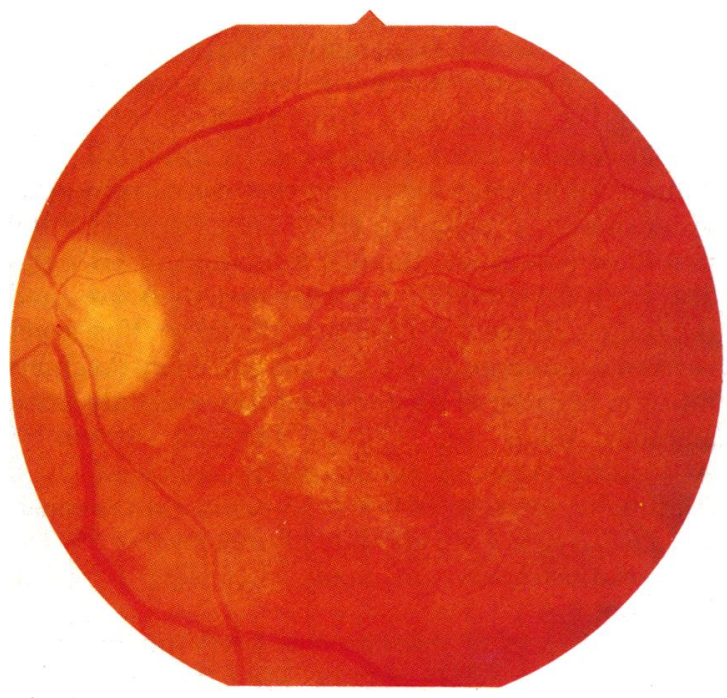

Fig. 6A

Figs. 6A, B After 19 days' treatment with Foscarnet there was partial improvement in the retinopathy, but retinal infiltration remained here and in other areas of both eyes. The drug produced marked superficial thrombophlebitis at intravenous cannula sites. superficial thrombophlebitis at the infusion sites, which made peripheral venous access increasingly difficult. No other adverse responses to this treat-

BW B759U $7.5 \mathrm{mg} / \mathrm{kg} /$ day was then given for 14 days, with marked improvement (Figs. 7A, B, 5 March 1986), and this time the patient was dis-

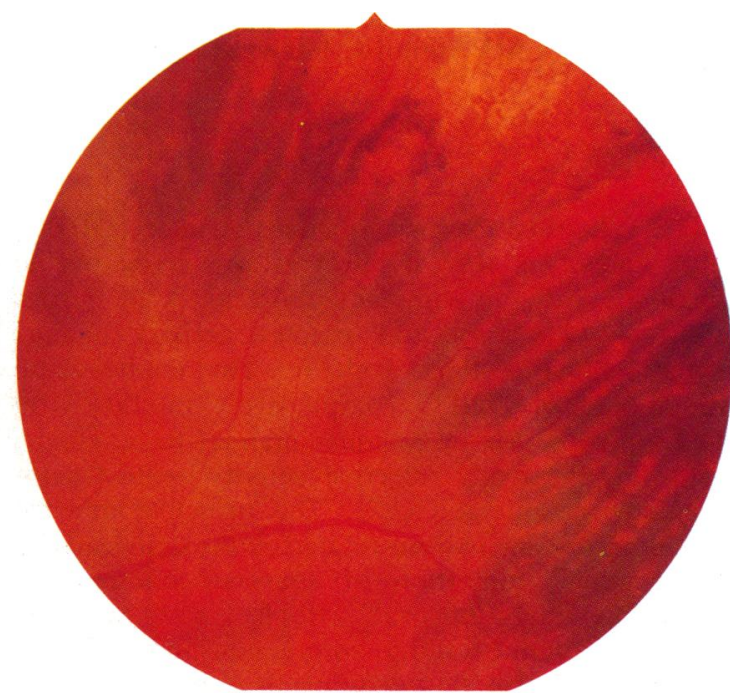

Fig. 6B ment were observed. 


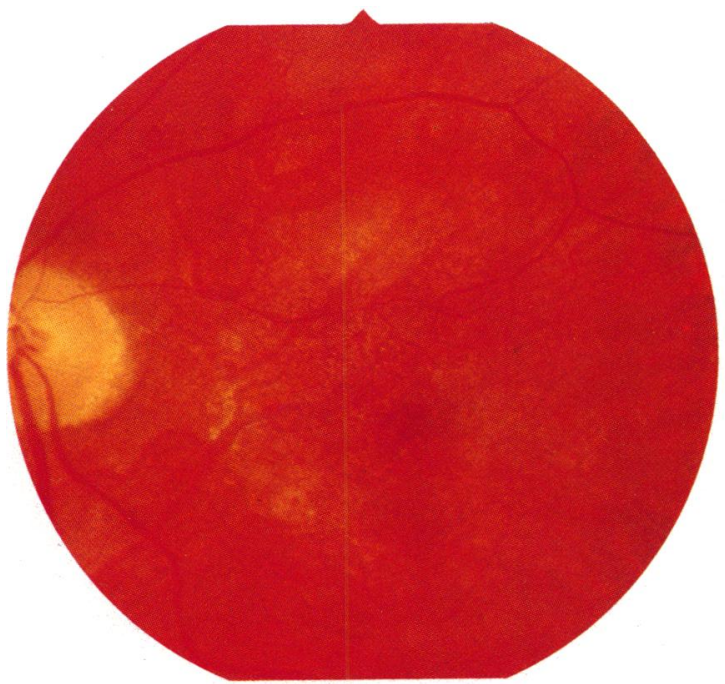

Fig. 7A

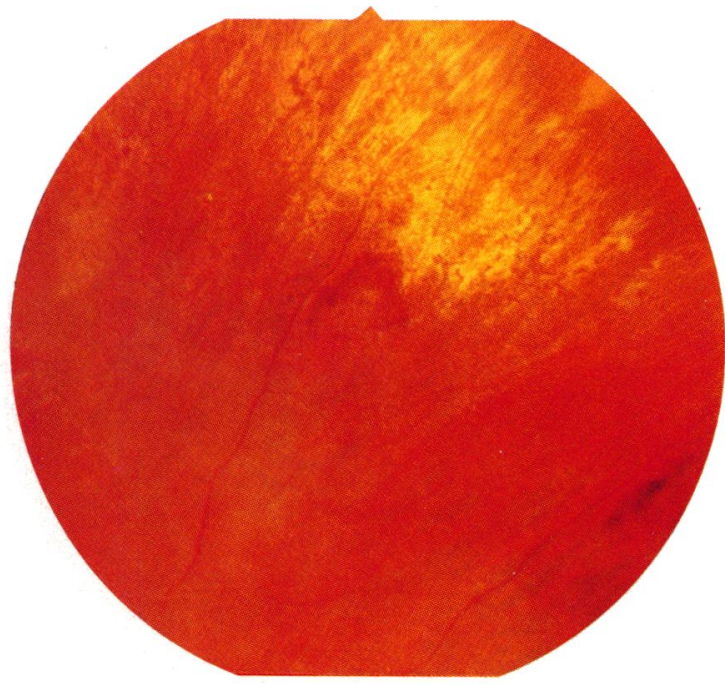

Fig. 7B

Figs. 7A, B A third course of DHPG cleared the retinitis, leaving areas of marked retinal atrophy.

charged on a maintenance regimen of $5 \mathrm{mg} / \mathrm{kg}$ three times weekly. The retinal lesions remained stable for six weeks, when the patient was readmitted because of fresh retinitis, weight loss, malaise, and salmonellosis. DHPG $7.5 \mathrm{mg} / \mathrm{kg} /$ day was given for 21 days. The patient died on 12 May. The course of the retinitis and treatment periods are summarised in Fig. 8.

At necropsy, the cause of death was found to be bronchopneumonia. Histology supported the clinical diagnosis of CMV retinitis, but viral cultures were negative.

\section{Discussion}

9-(1,3-Dihydroxy-2-propoxymethyl) guanine (DHPG, also known as BW B759U) is an acrylic purine analogue with antiviral activity against all herpes viruses, with a 30-fold greater activity against cytomegalovirus than acylovir. The triphosphate metabolite of DHPG competitively inhibits viral DNA polymerase in a similar manner to acyclovir, affording relatively selective activity against cytomegalovirus infected cells. The principal adverse reactions are due to dose-related cytotoxicity causing neutropenia, inhibition of spermatogenesis, and gastrointestinal mucosal atrophy and necrosis. DHPG is administered by intravenous infusion over one hour, and a therapeutic effect is achieved in doses of $2.5 \mathrm{mg}$ to $15 \mathrm{mg} / \mathrm{kg} /$ day given in two or three divided doses. "11 Shepp et al. ${ }^{12}$ have shown that neutropenia developed when mean peak and trough plasma levels exceded 50 and $10 \mu \mathrm{mol} / \mathrm{l}$ respectively, and that these levels were found in three out of five patients receiving $15 \mathrm{mg} / \mathrm{kg} / \mathrm{day}$ and in none receiving $7.5 \mathrm{mg} / \mathrm{kg} /$ day. However, others ${ }^{13}$ have reported neutropenia in two out of six patients at doses of 7.5 $\mathrm{mg} / \mathrm{kg} / \mathrm{day}$. Penetration of the central nervous system is high, with levels $38 \%$ of simultaneous blood levels, and $91 \%$ of the daily dose is excreted unchanged in the urine. ${ }^{12}$

Trisodium phosphoformate hexahydrate (Foscarnet) is an agent with activity against reverse transcriptase from a large number of retroviruses and DNA polymerases from herpes simplex types 1 and 2 and CMV. At plasma concentrations of 32-55 $\mu \mathrm{mol} / \mathrm{l}$ cellular DNA polymerase is inhibited. Cell cultures of herpes viruses and the animal retrovirus visna (which is related to HIV) are inhibited by 100 $\mu \mathrm{mol} / \mathrm{l}$ of Foscarnet. In-vitro inhibition of HIV has also been described..$^{1+15}$ Cellular toxicity is low, and the drug is eliminated rapidly in the urine. Foscarnet is given continuously as a $2 \%$ solution by intravenous infusion because of its short half-life, and only small amounts enter the central nervous system. ${ }^{14}{ }^{15}$ A loading dose of $10-20 \mathrm{mg} / \mathrm{kg}$ followed by a continuous infusion of $0.5-0.15 \mathrm{mg} / \mathrm{kg} / \mathrm{min}$ is calculated to achieve a steady state plasma level of 50-150 $\mu \mathrm{g} / \mathrm{l}$. Adjustments are made according to renal function. ${ }^{16}$

Clinical cases of resolution of CMV pneumonitis and retinitis in AIDS patients after the administration of DHPG have recently been reported from North America. ${ }^{121317-20}$ This year the Collaborative DHPG Study Group has reported resolution of disease activity and clearance of viraemia in nine out 
CHART SHOWING VISUAL ACUITIES AND TREATMENT PERIODS WITH DHPG AND FOSCARNET

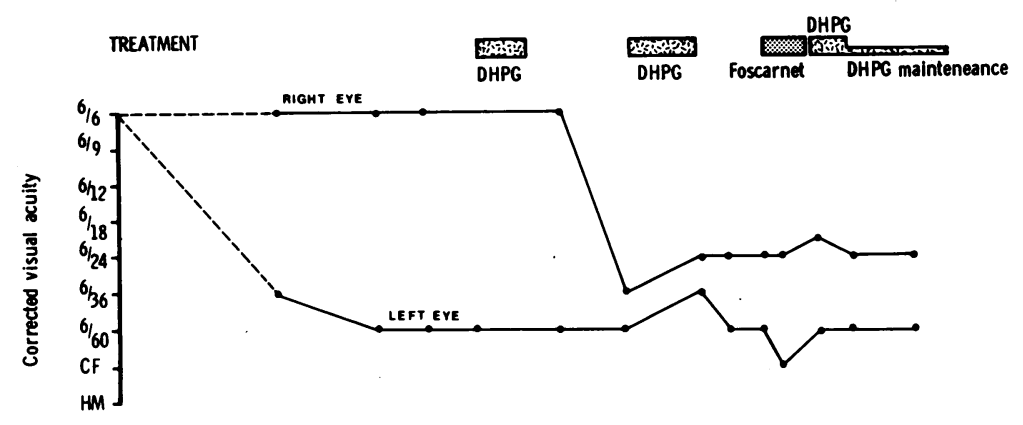

Fig. 8 Flow chart of the patient's treatment and visual acuity.

Date

1985 May June July Aug Sept Oct Now Dec Jan Feb March April 1986

of 11 patients with CMV retinitis. ${ }^{19}$ Palestine et al. ${ }^{20}$ reported the results of treatment with DHPG of 14 eyes in eight patients with CMV retinitis, eight of which demonstrated more than $90 \%$ resolution and four a partial response. Two out of these patients had chemotherapy induced immunosuppression and achieved remission for two and six months respectively. The remaining six patients had AIDS. Three were followed up and relapsed within 32 days of stopping treatment. One went on to further treatment, followed by maintenance therapy in reduced doses because of neutropenia and died four months after presentation. Rosencan et al. ${ }^{13}$ reported a response in all of a group of six patients with AIDS. Three relapsed within 21-28 days of cessation of treatment and three were lost to follow-up. Further treatment of one patient again was limited by drug induced neutropenia. These studies indicate that an initial response to DHPG is often obtained but that early clinical and virological relapse is common and that reversible neutropenia is the principal adverse reaction.

Reports of the clinical efficacy of Foscarnet in the treatment of disseminated CMV infection in the immunodeficient have appeared recently. ${ }^{2122}$ However, there is only one report of the treatment of CMV retinitis in AIDS. Singer et al. ${ }^{23}$ describe satisfactory resolution in one patient who also received adjunctive cytomegalovirus hyperimmune globulin and emphasise the relatively long remission of five months which was obtained.

We report a more satisfactory response to DHPG than to Foscarnet without using hyperimmune globulin. This apparent superiority may relate to limited penetration of the blood-brain barrier by Foscarnet. ${ }^{19}$ Our experience was similar to others' in that, although the retinitis responded initially to treatment, relapse invariably occurred $4-8$ weeks later. ${ }^{1318-211}$ Maintenance therapy with three times weekly DHPG did not affect the relapse time in our patient. Although Bach et al. ${ }^{18}$ reported a remission of over eight weeks in one patient, the role of maintenance treatment, its frequency, and the dosage require further clarification, especially in view of the practical problems associated with intravenous therapy in AIDS patients.

We are grateful to Syntex Research for supplying the DHPG, to Burroughs Welcome for the BW B759U, and to Astra Pharmaceuticals for the Foscarnet.

The fundus photographs were taken by Mr Richard Dewhirst, and Astra Pharmaceuticals kindly made a donation towards the costs of photographic reproduction.

\section{References}

1 Holland GN, Gottlieb MS, Yee RD, Schanker HM, Pettit TH. Ocular disorders associated with a new severe acquired immunodeficiency syndrome. Am J Ophthalmol 1982; 93: 393-402.

2 Rosenberg PR, Uliss AE, Friedland GH, Harris CA, Small CB, Klein RS. Acquired immunodeficiency syndrome: ophthalmic manifestations in ambulant patients. Ophthalmology 1983; 90: 874-8.

3 Freeman WR, Lerner CW, Mines JA, et al. A prospective study of the ophthalmic findings in the acquired immune deficiency syndrome. Am J Ophthalmol 1984; 97: 133-42.

4 Holland GN, Pepose JS, Pettit TH, Gottlieb MS, Yee RD, Foos RY. Acquired immune deficiency syndrome: ocular manifestations. Ophthalmology 1983; 90: 859-72.

5 Cole EL, Meisler DM, Calabrese LH, Holland GN, Mondino BY, Conant MA. Herpes zoster ophthalmicus and acquired immune deficiency syndrome. Arch Ophthalmol 1984; 102: $1027-9$.

6 Pepose JS, Hilbourn LH, Cancilla PA, Foos RY. Concurrent herpes simplex and cytomegalovirus retinitis and encephalitis in the acquired immune deficiency syndrome. Ophthalmology 1984; 91: 1669-77.

7 Newman NM, Mandel MR, Gullet J, Fujikawa L. Clinical and histological findings in opportunistic ocular infections: part of a new syndrome of acquired immunodeficiency. Arch Ophthalmol 101: 396-401. 
8 Pepose JS, Holland GN, Nestor MS, Cochrane AJ, Foos RY Acquired immune deficiency syndrome: pathogenic mechanisms of ocular disease. Ophthalmology 1985; 92: 472-84.

9 Friedman AH, Orellana J, Freeman WR, et al. Cytomegalovirus retinitis: a manifestation of the acquired immune deficiency syndrome. BrJ Ophthalmol 1983; 67: 372-80.

10 Elion GB, Furman PA, Fyfe JA, Demiranda L, Beauchamp L. Selectivity of action of an antiherpetic agent 9-(2hydroxyethoxymethoxy methyl) guanine. Proc Natl Acad Sci USA 1977, 74: 5714.

11 Martin JC, Dvorak CA, Smee DE, Mathews TR, Verheyden JPH. 9-((1,3-Dihydroxy-2-propoxy)methyl) guanine: a new potent and selective anti-herpes agent. J Med Chem 1983; 26: 759-61.

12 Shepp DH, Dandliker PS, de Miranda P, Cedenberg DM, Kirk E, Meyers JD. Activity of 9-((1,3-dihydroxy-2-propoxy)methyl) guanine in the treatment of cytomegalovirus pneumonia. Ann Intern Med 1985; 103: 368-73.

13 Rosencan LR, Stahl-Baylis CM, Kalman CM, Laskin OL. Antiviral therapy for cytomegalovirus retinitis in AIDS with dihydroxy propoxymethyl guanine. Am J Ophthalmol 1986; 101: 405-18.

14 Oberg B. Antiviral effects of phosphonoformate (PFA, Foscarnet sodium). Pharmacol Ther 1983; 19: 387-415.

15 Sandstrom EG, Byington RE, Kaplam JC, Hirsch MS. Inhibition of human T-cell lymphotrophic virus type III in vitro by phosphonoformate. Lancet 1985; i: 1480-2.
16 Klintman G, Lonnqvist B, Oberg B, et al. Intravenous Foscarnet for the treatment of severe cytomegalovirus infection in allograft recipients. Scand J Infect Dis 1985; 17: 157-63.

17 Felsenstein D, D'Amico DJ, Hirsch MS, et al. Treatment of cytomegalovirus retinitis with 9-((1,3-dihydroxy-2-propoxy) methyl) guanine. Ann Intern Med 1985; 103: 377-80.

18 Bach MC, Bagwell SP, Knapp NP, Davis KM, Hedstrom PS. 9((1,3-Dihydroxy-2-propoxy)methyl) guanine in patients with the acquired immunodeficiency syndrome. Ann Intern Med 1985; 103: $381-2$.

19 Collaborative DHPG Treatment Study Group. Treatment of serious cytomegalovirus infections with 9-(1,3-propoxy-2methyl) guanine in patients with AIDS and other immunodeficiencies. N Engl J Med 1986; 314: 801-5.

20 Palestine AG, Stevens G, Clifford Lane H, et al. Treatment of cytomegalovirus retinitis with dihydroxy propoxymethyl guanine. Am J Ophthalmol 1986; 101: 95-101.

21 Ringden O, Wilczek H, Lonnqvist B, Gahrton G, Wahren B, Lernestdt JO. Foscarnet for cytomegalovirus infections. Lancet 1985; ii: $1503-4$.

22 Apperley JF, Marcus RE, Goldman JM, Wardle DG, Gravett PJ, Chanas A. Foscarnet for cytomegalovirus pneumonitis. Lancet 1985 ; i: 1151.

23 Singer DR, Fallon TJ, Schulenberg WE, Williams G, Cohen J. Foscarnet for cytomegalovirus retinitis. Ann Intern Med 1985; 103: 962 .

Accepted for publication 28 October 1986. 